\title{
Antimicrobial Resistance Profiles for Different Isolates in Aden, Yemen: A Cross-Sectional Study in a Resource-Poor Setting
}

\author{
Wafa F. S. Badulla ${ }^{1},{ }^{1}$ Mohammed Alshakka, ${ }^{2}$ and Mohamed Izham Mohamed Ibrahim ${ }^{3}{ }^{3}$ \\ ${ }^{1}$ Department of Analytical Chemistry, Faculty of Pharmacy, Aden University, Aden, Yemen \\ ${ }^{2}$ Section of Clinical Pharmacy, Faculty of Pharmacy, Aden University, Aden, Yemen \\ ${ }^{3}$ Department of Clinical Pharmacy and Practice, College of Pharmacy, QU Health, Qatar University, Doha, Qatar
}

Correspondence should be addressed to Mohamed Izham Mohamed Ibrahim; mohamedizham@qu.edu.qa

Received 11 February 2020; Accepted 2 April 2020; Published 22 April 2020

Academic Editor: Pere Domingo

Copyright (c) 2020 Wafa F. S. Badulla et al. This is an open access article distributed under the Creative Commons Attribution License, which permits unrestricted use, distribution, and reproduction in any medium, provided the original work is properly cited. The publication of this article was funded by Qatar National Library.

\begin{abstract}
Background. There is a rapid deterioration in the effectiveness of antibiotics due to the global prevalence of bacterial antimicrobial resistance (AMR). AMR can cause an increase in mortality and morbidity due to treatment failures and a lack of effective therapy. Objective. The purpose of this study was to evaluate the AMR pattern of different bacterial isolates at hospitals and laboratories. Materials and Methods. A cross-sectional study from March 2019 to June 2019 was conducted at different governmental and private hospitals and laboratories in Aden, Yemen. Age, sex, specimen type, bacterial isolates, and antibiotic susceptibility pattern were collected using a data extraction sheet. Descriptive statistics were used for data analysis. Result. Data were recorded for 412 patients from whom 20 clinical specimens were collected and analyzed. The most common bacteria isolated were Staphylococcus spp. ( $n=172,41.74 \%)$, E. coli $(n=164,39.80 \%)$, Pseudomonas spp. $(n=37,8.98 \%)$, and Klebsiella pneumoniae $(n=18,4.36 \%)$; other bacteria were less common. The overall bacterial resistance was highest against the combination of sulfamethoxazole with trimethoprim (73.12\%), followed by amoxicillin and clavulanate $(65.19 \%)$. The cephalosporin antibiotics also showed high resistance rates. The study also showed moderate bacterial resistance to gentamycin (32.65\%), azithromycin (29.92\%), cefoxitin (62.65\%), and ciprofloxacin (25.60\%). Ertapenem (16.67\%) and levofloxacin (15.56\%) had the lowest resistance rates. Conclusion. There was a high percentage of bacteria resistant to several antibiotics. Antibiotic susceptibility testing is a prerequisite guide for the selection of appropriate antibiotic therapy for bacterial infections.
\end{abstract}

\section{Introduction}

The problem of widespread resistant bacteria has become a major threat to reduce the effectiveness of antibiotics worldwide [1-3]. The emergence of multiresistant organisms is escalating, especially in the developing world [4]. As stated by the WHO, there is a global need to increase awareness about antimicrobial resistance (AMR) [5-7]. This awareness and monitoring of AMR will be reflected in several aspects involving reporting the bacterial resistance rate, a guide for the selection of suitable antibiotics, and reducing hospitalization frequency, treatment costs, and the death rate [8-10].

To obtain information about the AMR in a country, there should be continuous surveillance that involves the collection of antimicrobial susceptibility testing (AST) results carried out by microbiology laboratories on clinical specimens. The obtained data provide insight into the prevalence of antibiotic-resistant bacteria in that country and help in decision-making, mainly the selection of antibiotics to be applied either for empirical treatment of sick patients or prophylaxis in patients at enhanced risk of infection. The national treatment guidelines should be updated according to the new data.

In Yemen, due to low income, most physicians try to reduce the cost of laboratory tests by treating patients according to previous clinical experience (i.e., empirical therapy) without the use of diagnostic testing, which should be performed by laboratory professionals. The situation may have been effective before the wide spread of resistant 
microorganisms. However, due to the serious risks of multiresistant organisms, a guide for the selection of appropriate antibiotics for patients' illnesses should be provided by the assistance of an effective laboratory system instead of depending on empirical therapy (irrational use of antibiotics). Information on infection epidemiology and antimicrobial resistance patterns is a critical means to help physicians empirically treat life-threatening infectious illnesses. Several studies reported a correlation between increasing the AMR rate and increasing antibiotic use [4, 11-14].

In a study performed in 2015 to explore the antibioticprescribing manner of physicians in outpatient sectors of hospitals in Aden, Yemen, the number of prescriptions containing antibiotics was $84.2 \%$, which is far from the standard values suggested by the WHO [15].

Another problem that faces Yemen is counterfeit medicines, and the smuggling of medicine is widespread as well. According to a study carried out in Yemen, approximately $80 \%$ of medicines entered the country via illegal routes, and approximately $40 \%$ were fake or of low quality [16]. According to the WHO, approximately $43 \%$ of falsified antibiotics have no active ingredients, $24 \%$ are of bad quality, $21 \%$ have a reduced quantity of an active ingredient, and $7 \%$ have wrong ingredients [17]. The quality control of antibiotics is a very significant issue because counterfeit-quality generic antibiotics may contribute to the emergence of resistant bacteria [18].

The main aim of the current study was to determine the different AMR patterns of bacterial isolates from different specimens at various government and private hospitals as well as diagnostic service laboratories in Aden, Yemen. Findings from this study will guide the rational use of the existing antimicrobials and guide optimal empiric treatment in critically ill patients.

\section{Materials and Methods}

2.1. Study Design. A cross-sectional study was carried out from March 2019 to June 2019. The study was conducted at different governmental and private hospitals and laboratories in Aden, Yemen: National Blood Transfusion and Research Center, Al-Medina Medical Laboratories, Babel Hospital, and Aden German International Hospital. The patient data were collected from the microbiology laboratory unit registration book. Age, sex, specimen type, bacterial isolates, and antibiotic susceptibility pattern were collected using a data extraction sheet.

2.2. Isolation and Identification of Bacteria. All clinical samples were collected and identified for pathogenic bacteria by standard microbiological techniques. According to the source of clinical specimens, each sample was placed onto the specific agar for each bacterium (HiMedia Laboratories Pvt. Limited, India) and then incubated aerobically at $37^{\circ} \mathrm{C}$ for $24 \mathrm{~h}$. Standard microbiological methods were applied for the identification of the bacterial species [19].

2.3. Antimicrobial Susceptibility Testing. Antimicrobial susceptibility tests were carried out by all laboratories using the disk diffusion method [20].
TABLE 1: Sex, patient category, and laboratory distribution.

\begin{tabular}{lcc}
\hline & Frequency & Percentage \\
\hline Gender & & \\
$\quad$ Male & 178 & 43.2 \\
$\quad$ Female & 234 & 56.8 \\
Patient category & & \\
$\quad$ Child & 57 & 13.8 \\
$\quad$ Adult & 355 & 86.2 \\
Study location & & \\
$\quad$ National Blood Transfusion and & 35 & 8.5 \\
Research Center & 234 & 56.8 \\
Al-Medina medical laboratories & 41 & 10.0 \\
Babel Hospital & 102 & 24.8 \\
Aden German International Hospital & & \\
\hline
\end{tabular}

2.4. Quality Control. A standard bacteriological technique was applied to maintain accurate laboratory test results. American Type Culture Collection (ATCC) standard reference strains Escherichia coli (E. coli) ATCC-25922, Staphylococcus aureus (S. aureus) ATCC 25923, and Pseudomonas aeruginosa ( $P$. aeruginosa) ATCC 25853 were used to control the quality of culture and drug susceptibility testing.

2.5. Data Analysis. Statistical Package for Social Sciences (SPSS) version 21 (IBM Corp. released 2012; IBM SPSS Statistics for Windows, version 21.0, Armonk, NY: IBM Corp.) was used for both data entry and analysis. Descriptive statistics were used to determine the frequency of isolated bacteria. The antibiotic susceptibility to the used antibiotics was analyzed.

2.6. Ethical Consideration. The study protocol was approved by the Ethics Research Committee of the Faculty of Medicine and Health Sciences, Aden University (research code: REC-61-2019).

\section{Results and Discussion}

3.1. Study Population and Laboratory Distribution. A total of 412 recorded patient data points were collected from four laboratories. A majority of samples $(234,56.8 \%)$ were collected from female patients, and 178 (43.2\%) were collected from male patients. A higher isolation rate was obtained from adults than from children $(n=355,86.2 \%)$ (see Table 1$)$.

3.2. Bacterial Isolates. The distribution of bacterial isolates with the associated specimens is illustrated in Table 2. In this study, a total of 20 clinical specimens were collected from various clinical specimens. The most common specimens processed in the different laboratories were urine $(n=150$, $36.4 \%)$, followed by pus swabs $(n=69,16.7 \%)$ and wound swabs $(n=50,12.1 \%)$. The majority of the bacterial isolates were recovered from the urine specimens. The most common bacteria isolated were Staphylococcus spp. $(n=172,41.74 \%)$, E. coli $(n=164,39.80 \%)$, Pseudomonas spp. $(n=37,8.98 \%)$, and Klebsiella pneumoniae $(n=18,4.36 \%)$. 
TABLE 2: Distribution of bacterial isolates with the specimens.

\begin{tabular}{|c|c|c|c|}
\hline Specimen & Bacteria & $n(\%)$ & Total \\
\hline \multirow{9}{*}{ Urine } & E. coli & $90(60 \%)$ & \multirow{9}{*}{150} \\
\hline & Staphylococcus species & $38(25.33 \%)$ & \\
\hline & Pseudomonas species & $13(8.66 \%)$ & \\
\hline & Enterobacter species & $2(1.33 \%)$ & \\
\hline & Enterococci species & $1(0.66 \%)$ & \\
\hline & Klebsiella pneumoniae & $2(1.33 \%)$ & \\
\hline & Candida albicans & $2(1.33 \%)$ & \\
\hline & Streptococcus species & $1(0.66 \%)$ & \\
\hline & Sphingomonas paucimobilis & $1(0.6 \%)$ & \\
\hline \multirow{3}{*}{ Plural } & Staphylococcus species & $3(50 \%)$ & \multirow{3}{*}{6} \\
\hline & Salmonella Paratyphi A & $2(33.33 \%)$ & \\
\hline & E. coli & $1(16.67 \%)$ & \\
\hline \multirow{4}{*}{ Ear swab } & Staphylococcus species & $16(72.72 \%)$ & \multirow{4}{*}{22} \\
\hline & Pseudomonas species & $3(13.63 \%)$ & \\
\hline & Proteus species & $2(9.09 \%)$ & \\
\hline & E. coli & $1(4.54 \%)$ & \\
\hline \multirow{7}{*}{ Wound swab } & Staphylococcus species & $25(49.01 \%)$ & \multirow{7}{*}{51} \\
\hline & E. coli & $14(27.45 \%)$ & \\
\hline & Pseudomonas species & $4(7.84 \%)$ & \\
\hline & Proteus species & $3(5.88 \%)$ & \\
\hline & Streptococcus species & $2(3.92 \%)$ & \\
\hline & Klebsiella pneumoniae & $2(3.92 \%)$ & \\
\hline & Enterobacter species & $1(1.96 \%)$ & \\
\hline \multirow{3}{*}{ Throat swab } & Staphylococcus species & $2(40 \%)$ & \multirow{3}{*}{5} \\
\hline & Streptococcus species & $2(40 \%)$ & \\
\hline & Klebsiella pneumoniae & $1(20 \%)$ & \\
\hline \multirow{5}{*}{ Vaginal swab } & Staphylococcus species & $16(42.10 \%)$ & \multirow{5}{*}{38} \\
\hline & E. coli & $15(39.47 \%)$ & \\
\hline & Klebsiella pneumoniae & $3(7.89 \%)$ & \\
\hline & Pseudomonas species & $3(7.89 \%)$ & \\
\hline & Candida albicans & $1(2.63)$ & \\
\hline \multirow{2}{*}{ Nasal swab } & Staphylococcus species & $3(75 \%)$ & \multirow{2}{*}{4} \\
\hline & E. coli & $1(25 \%)$ & \\
\hline \multirow{5}{*}{ Sputum } & E. coli & $3(37.5 \%)$ & \multirow{5}{*}{8} \\
\hline & Pseudomonas species & $2(25.00 \%)$ & \\
\hline & Klebsiella pneumoniae & $1(12.50 \%)$ & \\
\hline & Enterobacter species & $1(12.50 \%)$ & \\
\hline & Candida albicans & $1(12.50 \%)$ & \\
\hline \multirow{2}{*}{ Blood } & Staphylococcus species & $13(92.85 \%)$ & \multirow{2}{*}{14} \\
\hline & Pseudomonas species & $1(7.14 \%)$ & \\
\hline \multirow{2}{*}{ Cervical secretion } & Staphylococcus species & $2(66.66 \%)$ & \multirow{2}{*}{3} \\
\hline & E. coli & $1(33.33 \%)$ & \\
\hline Skin specimen & Pseudomonas species & $3(100 \%)$ & 3 \\
\hline
\end{tabular}


TABLE 2: Continued.

\begin{tabular}{|c|c|c|c|}
\hline Specimen & Bacteria & $n(\%)$ & Total \\
\hline \multirow{4}{*}{ Pus swab } & Staphylococcus species & $41(59.42 \%)$ & \multirow{4}{*}{69} \\
\hline & E. coli & $20(28.98 \%)$ & \\
\hline & Klebsiella pneumonia & $4(5.79 \%)$ & \\
\hline & Pseudomonas species & $4(5.79 \%)$ & \\
\hline Nasopharynges & Staphylococcus species & $4(100 \%)$ & 4 \\
\hline \multirow{3}{*}{ Semen } & Staphylococcus species & $6(66.66 \%)$ & \multirow{3}{*}{9} \\
\hline & Klebsiella pneumoniae & $2(22.22 \%)$ & \\
\hline & Pseudomonas species & $1(11.11 \%)$ & \\
\hline \multirow{2}{*}{ Cerebrospinal fluid } & Pseudomonas species & $3(75 \%)$ & \multirow{2}{*}{4} \\
\hline & E. coli & $1(25 \%)$ & \\
\hline \multirow{2}{*}{ Stool } & E. coli & $16(88.88 \%)$ & \multirow{2}{*}{18} \\
\hline & Staphylococcus species & $2(11.11 \%)$ & \\
\hline Catheter swab & Candida albicans & $1(100 \%)$ & 1 \\
\hline Eye swab & Staphylococcus species & $1(100 \%)$ & 1 \\
\hline Tracheostomy swab & Pseudomonas species & $1(100 \%)$ & 1 \\
\hline Rectal swab & E. coli & $1(100 \%)$ & 1 \\
\hline
\end{tabular}

3.3. Antibiotic Nonsusceptibility. A total of 63 antibiotics were screened by AST. The most frequently tested antibiotics were studied for their AMR (Table 3). The table summarizes the bacterial resistance patterns for the selected antibiotics. The overall resistance rate was highest in the case of the sulfamethoxazole and trimethoprim combination, at $73.12 \%$, while the lowest resistance rate was observed for ertapenem (carbapenem antibiotic), at $16.67 \%$.

AMR in Yemen can cause an increase in mortality and morbidity due to treatment failures and lack of effective therapy. Moreover, in a country with poor resources, such as Yemen, the economic consequences may be even more detrimental, as increased treatment costs consume funds. The development of highly resistant pathogens is the inevitable outcome for the frequent, irrational use of broadspectrum antibiotics as well as the availability of antibiotics as over-the-counter medicines in this city. The present study provides an outline of the existing resistance level that can be used as a guide for effective treatment. The data were collected from four main hospitals and laboratories in this city. Each laboratory throughout the study period reported variable numbers of antimicrobial-resistant bacterial strains from approximately 20 different kinds of medical specimens. The bacterial isolate distribution and frequency varied in different clinical specimens. The number of male patients was higher than that of female patients, and the number of adults was higher than that of children.

The findings from the current study revealed the distribution of bacterial isolates with the specimens and the AMR patterns for different pathogenic isolates. The key outcome is the prevalence of Staphylococcus spp. in the main specimens (urine, wound, ear, nasal, vaginal swab, etc.), at $41.74 \%$. This finding is similar to that in a study carried out in Gabon and Tanzania [21-23]. Additionally, E. coli and Pseudomonas spp. were dominant in the isolates. These species are commensal bacteria that can be present as normal flora on different parts of healthy individuals. However, these bacteria can be pathogenic and readily disseminated. The high variety of pathogens isolated from different specimens indicated the ineffectiveness of using empirical antibiotic therapy and supported the use of susceptibility tests before prescribing antibiotic therapy. However, these data can be a guide for empirical antibiotic therapy for the most predominant pathogens for different specimens.

The findings show the bacterial resistance patterns to the selected antibiotics. The highest overall resistance was for the combination of sulfamethoxazole with trimethoprim (cotrimoxazole), followed by amoxicillin and clavulanate, which could be due to recurrent empirical therapy with these combinations prior to sampling. The majority of bacteria resistant to sulfamethoxazole and trimethoprim were gramnegative species, namely, E. coli, Klebsiella spp., and Pseudomonas spp., while in the case of amoxicillin and clavulanate, most bacteria (gram negative and positive) had a high percent of resistance. The result for cotrimoxazole is identical to that in a study in Ghana, but it is dissimilar for amoxicillin and clavulanate; the study revealed a low level of resistance to amoxicillin and clavulanate [24].

In addition, some of the cephalosporin antibiotics had high resistance percentages, such as cefepime $64.60 \%$, ceftriaxone $62.20 \%$, cefuroxime $54.36 \%$, and ceftazidime $47.54 \%$. This finding is an indication of the irrational use of new and strong antibiotics for simple infectious or even viral diseases that leads to widespread bacterial resistance to these antibiotics. This result is aligned with 2014 WHO reports [25]. Since 2004, resistance to cephalosporins has increased seriously for Escherichia coli infections [26]. In addition, parallel findings were obtained from studies carried out in Iraq, Pakistan, and Ethiopia [27-30]. 
TABLE 3: Bacterial resistance patterns to the selected antibiotics.

\begin{tabular}{|c|c|c|c|c|c|c|c|}
\hline \multirow[b]{2}{*}{ Type of isolate } & \multicolumn{7}{|c|}{ Antimicrobial nonsusceptibility } \\
\hline & $\begin{array}{c}\text { Amoxicillin } \\
\text { with clavulanate } \\
N / \text { total (\%) }\end{array}$ & $\begin{array}{l}\text { Ampicillin } \\
\text { with sulbactam } \\
N / \text { total }(\%)\end{array}$ & $\begin{array}{l}\text { Azithromycin } \\
\text { N/total (\%) }\end{array}$ & $\begin{array}{l}\text { Cefepime } \\
\text { N/total (\%) }\end{array}$ & $\begin{array}{l}\text { Cefotaxime } \\
N / \text { total (\%) }\end{array}$ & $\begin{array}{c}\text { Cefoxitin } \\
\text { N/total (\%) }\end{array}$ & $\begin{array}{l}\text { Ceftriaxone } \\
N / \text { total (\%) }\end{array}$ \\
\hline Klebsiella species & $5 / 8(62.50)$ & $0 / 1(0)$ & $2 / 6(33.33)$ & $5 / 7(71.43)$ & $2 / 6(33.33)$ & $1 / 4(25.00)$ & $0 / 3(0)$ \\
\hline E. coli & $71 / 98(72.40)$ & $8 / 20(40.00)$ & $7 / 23(30.43)$ & $61 / 89(68.54)$ & $76 / 111(68.47)$ & $23 / 85(27.05)$ & $77 / 114(32.45)$ \\
\hline $\begin{array}{l}\text { Pseudomonas } \\
\text { species }\end{array}$ & $24 / 27(88.88)$ & $4 / 5(80.00)$ & $1 / 9(11.11)$ & $14 / 24(58.33)$ & $7 / 7(100)$ & $6 / 8(75.00)$ & $9 / 13(69.23)$ \\
\hline $\begin{array}{l}\text { Staphylococcus } \\
\text { aureus }\end{array}$ & $10 / 16(62.50)$ & $1 / 31(3.22)$ & $27 / 85(31.76)$ & $20 / 33(60.60)$ & $14 / 29(48.27)$ & $12 / 65(18.46)$ & $17 / 33(51.51)$ \\
\hline $\begin{array}{l}\text { Streptococcus } \\
\text { species }\end{array}$ & $6 / 29(20.68)$ & $1 / 31(3.22)$ & $0 / 1(0)$ & $2 / 3(66.66)$ & $1 / 3(33.33)$ & ND & $1 / 2(50.00)$ \\
\hline Proteus species & $1 / 2(50.00)$ & ND & $1 / 2(50.00)$ & $0 / 3(0)$ & $0 / 4(0)$ & $1 / 2(50.00)$ & $0 / 2(0)$ \\
\hline $\begin{array}{l}\text { Enterobacter } \\
\text { species }\end{array}$ & $1 / 1(100)$ & ND & $0 / 1(0)$ & $1 / 1(100)$ & $3 / 3(100)$ & $0 / 1(0)$ & ND \\
\hline $\begin{array}{l}\text { Enterococcus } \\
\text { species }\end{array}$ & ND & ND & ND & ND & $1 / 1(100)$ & ND & ND \\
\hline $\begin{array}{l}\text { Salmonella } \\
\text { Paratyphi A }\end{array}$ & ND & ND & ND & ND & $1 / 1(100)$ & ND & $2 / 3(66.66)$ \\
\hline $\begin{array}{l}\text { Sphingomonas } \\
\text { paucimobilis }\end{array}$ & ND & ND & ND & $1 / 1(100)$ & $0 / 1(0)$ & $1 / 1(100)$ & ND \\
\hline \multirow[t]{2}{*}{ Total } & $118 / 181(65.19)$ & $21 / 97(21.65)$ & $38 / 127(29.92)$ & $104 / 161(64.60)$ & $104 / 166(62.65)$ & $44 / 166(26.50)$ & $107 / 172(62.20)$ \\
\hline & \multicolumn{7}{|c|}{ Antimicrobial nonsusceptibility } \\
\hline Type of isolate & $\begin{array}{c}\text { Ciprofloxacin } \\
\text { N/total (\%) }\end{array}$ & $\begin{array}{l}\text { Ceftazidime } \\
\text { N/total (\%) }\end{array}$ & $\begin{array}{l}\text { Cefuroxime } \\
\text { N/Total (\%) }\end{array}$ & $\begin{array}{l}\text { Ertapenem } \\
N / \text { total (\%) }\end{array}$ & $\begin{array}{l}\text { Gentamycin } \\
\text { N/total (\%) }\end{array}$ & $\begin{array}{c}\text { Levofloxacin } \\
\text { N/total (\%) }\end{array}$ & $\begin{array}{c}\text { Sulfamethoxazole } \\
\text { with trimethoprim } \\
\text { N/total (\%) }\end{array}$ \\
\hline Klebsiella species & $5 / 12(41.66)$ & $1 / 3(33.33)$ & $4 / 5(80.0)$ & $1 / 5(20.0)$ & $5 / 8(62.50)$ & $0 / 1(0)$ & $2 / 3(66.66)$ \\
\hline E. coli & 28/103 (27.18) & $12 / 29(41.38)$ & $19 / 26(73.07)$ & $6 / 89(93.25)$ & $9 / 23(39.13)$ & $11 / 40(27.5)$ & $57 / 75(76.0)$ \\
\hline $\begin{array}{l}\text { Pseudomonas } \\
\text { species }\end{array}$ & $10 / 28(35.71)$ & $8 / 17(47.05)$ & $14 / 19(73.68)$ & $3 / 4(74.0)$ & $5 / 16(31.25)$ & $0 / 13(0)$ & $9 / 15(60.0)$ \\
\hline $\begin{array}{l}\text { Staphylococcus } \\
\text { aureus }\end{array}$ & $19 / 95(20.0)$ & $7 / 11(63.63)$ & $15 / 45(33.33)$ & $9 / 17(52.94)$ & $12 / 45(26.66)$ & $9 / 73(12.32)$ & $49 / 66(74.24)$ \\
\hline $\begin{array}{l}\text { Streptococcus } \\
\text { species }\end{array}$ & ND & ND & $1 / 2(50.0)$ & $1 / 2(50.0)$ & $0 / 1(0)$ & ND & $0 / 1(0)$ \\
\hline Proteus species & $0 / 1(0)$ & ND & $1 / 2(50.0)$ & $0 / 2(0)$ & $0 / 1(0)$ & $0 / 2(0)$ & ND \\
\hline $\begin{array}{l}\text { Enterobacter } \\
\text { species }\end{array}$ & $1 / 5(20.0)$ & $1 / 1(100)$ & $1 / 1(100)$ & $0 / 1(0)$ & $0 / 1(0)$ & $1 / 2(50.0)$ & ND \\
\hline $\begin{array}{l}\text { Enterococci } \\
\text { species }\end{array}$ & ND & ND & $0 / 1(0)$ & ND & $1 / 2(50.0)$ & $0 / 2(0)$ & ND \\
\hline $\begin{array}{l}\text { Salmonella } \\
\text { Paratyphi A }\end{array}$ & $0 / 1(0)$ & ND & $1 / 2(50.0)$ & ND & ND & $0 / 2(0)$ & ND \\
\hline $\begin{array}{l}\text { Sphingomonas } \\
\text { paucimobilis }\end{array}$ & $0 / 1$ & ND & ND & ND & $0 / 1(0)$ & ND & ND \\
\hline Total & $63 / 246(25.60)$ & $29 / 61(47.54)$ & $56 / 103(54.36)$ & $20 / 120(16.67)$ & $32 / 98(32.65)$ & $21 / 135(15.56)$ & $117 / 160(73.13)$ \\
\hline
\end{tabular}

This study also showed moderate bacterial resistance toward gentamycin, azithromycin, cefoxitin, and ciprofloxacin. Klebsiella spp. showed the highest resistance to gentamycin $(62.50 \%)$, followed by E. coli $(39.13 \%)$. The resistance was lower than that in studies carried out in India, where the resistance of Klebsiella pneumoniae to gentamycin reached $80 \%$ in one study and $100 \%$ in another study. In the case of E. coli, the resistance ranged from $48.20 \%$ to $92.4 \%[31,32]$. The WHO GASP statistics of several countries from 2009 to 2014 presented continual prevalent gonococcal resistance to azithromycin, but azithromycin was still effective against Shigella sp. strains [33]. Cefoxitin is a second-generation cephalosporin and exhibited the lowest resistance rate among the cephalosporin generations tested in the current study.

Ciprofloxacin is used as a first-choice treatment for several infections, such as UTI, GIT infection, and typhoid, in Yemen. The widespread use of these antimicrobials in the treatment of community-acquired infections may have contributed to the high levels of observed resistance. The percentages of ciprofloxacin resistance were variable according to the site of bacterial infection as well as the geographical site. The resistance percentages are high in developing countries in comparison to those in developed countries. Klebsiella spp. showed the highest resistance rate, $41.66 \%$. A 
study carried out in Iran showed a $38.8 \%$ resistance rate of Klebsiella pneumoniae to ciprofloxacin [34] and approximately $28.5 \%$ in community-acquired UTI [35]. Another study conducted in India revealed that the resistance rate of Klebsiella pneumoniae to ciprofloxacin was $80 \%$ [36]. The current study showed that the resistance rate was $41.66 \%$, which is close to that in the study from Iran and lower than that in the study from India.

Levofloxacin and ertapenem had the lowest resistance rates. Several studies revealed increased resistance due to the frequent utilization of levofloxacin [37-39]. The low bacterial resistance to ertapenem might be due to its relatively new administration and low rate of prescription for infectious illness. Studies in Ethiopia and Colombia also reported low resistance to ertapenem $[40,41]$.

Enterococci spp. were detected in limited numbers and were not susceptible to antibiotics such as cefotaxime $(n=1 / 1,100 \%)$ and gentamycin $(n=1 / 2,50 \%)$. A study carried out in Iran on the occurrence of Enterococcus faecalis and Enterococcus faecium in several clinical samples indicated a nonsusceptible pattern toward rifampicin $(n=122,76.25 \%)$ as well as erythromycin ( $n=117,73.12 \%)$. The same study also showed the prevalence of virulent traits [42]. Another review study in Iran (2009 to 2015) revealed the emergence of Acinetobacter baumannii clinical specimens with high resistance to different classes of antibiotics (including carbapenems) [42]. The result of this study was in parallel with that of a study carried out in Iran (2015-2016) [43]. Multidrug-resistant Acinetobacter baumannii strains have become a worldwide problem [44]. Although this type of bacterium was not detected in any of the current study clinical specimens, it is possible that this type of bacterium would also show multidrug resistance if it was examined. Enterobacter spp. were resistant to amoxicillin with clavulanate $(n=1 / 1,100 \%)$, cefepime $(n=1 / 1,100 \%)$, cefotaxime $(n=3 / 3,100 \%)$, ceftazidime $(n=1 / 1,100 \%)$, cefuroxime $(n=1 / 1,100 \%)$, gentamycin $(n=1 / 2,50 \%)$, and ciprofloxacin $(n=1 / 5,20 \%)$. The results revealed that bacteria were highly resistant to the cephalosporin, with moderate resistance against gentamycin and relatively low resistance to ciprofloxacin. The results of a study in Iran on an Enterobacter cowanii isolate from powdered infant formula revealed susceptibility to imipenem, meropenem, ceftazidime, ciprofloxacin, and colistin. Fifty percent of isolates were resistant to ampicillin, amoxicillin, and cotrimoxazole [45].

It is worth mentioning that many bacteria had multidrug resistance to the most examined antibiotics. This finding corresponds with studies in Ethiopia [33, 46, 47]. It is an expected outcome due to the worldwide existence and prevalence of multidrug-resistant clones [48-50]. Similarly, a study in Iranian hospitalized patients with cancer showed significant spreading of MDR gram-negative bacteria, which may raise the problem of healthcare-associated infections in cancer patients [51, 52].

Initially, antibiotic-resistant bacteria were limited to hospitals; nevertheless, resistant strains of bacteria are currently present everywhere. It is expected that by 2050, none of the currently present antibiotics will be effective in treating infections. The situation will be tragic unless a new drug is developed or discovered [53].
Nevertheless, the prescription patterns should be altered to keep pace with the changes in bacterial resistance.

The comparison to the other studies is limited to the most similar due to the variance in the pattern and frequency of bacterial isolates among different clinical specimens in the present literature, which might be due to differences in study objectives, study designs, qualification methods, geographic dissimilarities, and discrepancies in the study populations. This report is considered the tip of the iceberg for the situation of bacterial resistance in Aden city. These results can serve as a basis for upcoming prospective and retrospective studies to have a clear idea about the change in bacterial resistance patterns over the years. In Yemen, antibiotics are important and often scarce resources. They are commonly unregulated, misused, and overused. There is a need to increase access to diagnostic laboratories, enhance surveillance of the emergence of $\mathrm{AMR}$, and conduct additional studies.

This study has a few limitations. First, the small sample size, which may not characterize the overall population, lived in the study area. Second, the sources of pathogens were indistinct; they were either community- or hospital-acquired infections. Furthermore, we could not obtain the history and state of the diseases if the patient used antibiotics before the susceptibility test or not. Epidemiological data (e.g., place of residence and the onset of disease) have not been reported.

Few recommendations can be considered based on the study findings. The outcome is worrisome and requires an extended study that involves all Yemeni cities to obtain a clear view of antimicrobial resistance. The effort of gathering information about the trends of bacterial resistance will be unprofitable if there are no local, national, and global strategies to provide effective interventions to reduce the prevalence of AMR, especially in a resource-poor setting. The following points should be taken into consideration: (1) a study with a larger sample size with more demographic, epidemiological, and health information of each patient should be conducted; (2) a retrospective study for the past 10 years is recommended to compare the bacterial resistance patterns; (3) there should be continuous surveillance of antibacterial resistance with regular reporting of data to the $\mathrm{WHO}$ and participation in the Global Antimicrobial Resistance Surveillance System (GLASS); and (4) diagnostic stewardship should be activated to provide appropriate interventions and application of suitable antimicrobial agents for the patient's infections.

\section{Conclusions}

The information within this study provides essential data on antimicrobial resistance in Aden, Yemen. This study revealed that Staphylococcus spp., followed by E. coli, Pseudomonas spp., and Klebsiella pneumoniae, were the most widespread pathogenic bacteria in several isolates. Overall bacterial resistance was common for old antibiotics, such as the combination of sulfamethoxazole with trimethoprim, followed by amoxicillin and clavulanate. Additionally, cephalosporin had a relatively higher resistance rate than other antibiotics. The study also showed moderate bacterial resistance toward gentamycin, azithromycin, cefoxitin, and ciprofloxacin. 
However, a lower percentage of resistance was present for the combination of ampicillin with sulbactam, ertapenem, and levofloxacin. Most isolated bacteria showed multidrug resistance. Consequently, antibiotic susceptibility testing is an important guide for the choice of suitable antibiotic treatment for bacterial infections.

\section{Data Availability}

Data can be obtained from the authors upon request.

\section{Conflicts of Interest}

The authors declare that there are no conflicts of interest regarding the publication of this article.

\section{References}

[1] S. C. Davies, T. Fowler, J. Watson, D. M. Livermore, and D. Walker, "Annual report of the chief medical officer: infection and the rise of antimicrobial resistance," The Lancet, vol. 381, no. 9878, pp. 1606-1609, 2013.

[2] World Health Organization, The Evolving Threat of Antimicrobial Resistance: Options for Action, World Health Organization, Geneva, 2012.

[3] Centres for Disease Control and Prevention (US), Antibiotic resistance threats in the United States, 2013, Centres for Disease Control and Prevention, US Department of Health and Human Services, 2013.

[4] S. B. Levy and B. Marshall, "Antibacterial resistance worldwide: causes, challenges and responses," Nature Medicine, vol. 10, no. S12, pp. S122-S129, 2004.

[5] A. Tsutsui and S. Suzuki, "Japan nosocomial infections surveillance (JANIS): a model of sustainable national antimicrobial resistance surveillance based on hospital diagnostic microbiology laboratories," BMC Health Services Research, vol. 18, no. 1, p. 799, 2018.

[6] Organization WH, "Global action plan on antimicrobial resistance," https://www.who.int/antimicrobial-resistance/ globalaction-plan/en/.

[7] Organization WH, "Global Antimicrobial Resistance Surveillance System (GLASS) Report: Early Implementation 20172018," https://www.who.int/drugresistance/surveillance/ GLASSmeeting/en/.

[8] L. Li, J.-x. Dai, L. Xu et al., "Antimicrobial resistance and pathogen distribution in hospitalized burn patients: a multicenter study in Southeast China," Medicine, vol. 97, no. 34, 2018.

[9] S. Gandra, N. Mojica, E. Y. Klein et al., "Trends in antibiotic resistance among major bacterial pathogens isolated from blood cultures tested at a large private laboratory network in India, 2008-2014," International Journal of Infectious Diseases, vol. 50, pp. 75-82, 2016.

[10] B. Aslam, W. Wang, M. I. Arshad et al., "Antibiotic resistance: a rundown of a global crisis," Infection and Drug Resistance, vol. 11, article 1645, 1658 pages, 2018.

[11] J. Turnidge and K. Christiansen, "Antibiotic use and resistance-proving the obvious," The Lancet, vol. 365, no. 9459, pp. 548-549, 2005.

[12] A. M. Shibl, Z. Memish, and A. Osoba, "Antibiotic resistance in developing countries," Journal of Chemotherapy, vol. 13, Supplement 1, pp. 40-44, 2001.
[13] D. Nasrin, P. J. Collignon, L. Roberts, E. J. Wilson, L. S. Pilotto, and R. M. Douglas, "Effect of beta lactam antibiotic use in children on pneumococcal resistance to penicillin: prospective cohort study," BMJ, vol. 324, no. 7328, pp. 28-30, 2002.

[14] M. Ferech, S. Coenen, S. Malhotra-Kumar et al., "European Surveillance of Antimicrobial Consumption (ESAC): outpatient antibiotic use in Europe," Journal of Antimicrobial Chemotherapy, vol. 58, no. 2, pp. 401-407, 2006.

[15] M. Alshakka, K. Said, M. Babakri et al., "A study on antibiotics prescribing pattern at outpatient department in four hospitals in Aden-Yemen," Journal of Pharmacy Practice and Community Medicine, vol. 2, no. 3, pp. 88-93, 2016.

[16] Z. Sallami, Y. Kassim, J. Selvaraj, E. Parry, and G. Winter, "Impact of the armed conflict of 2015-2016 in Aden on health services and the availability of medicines," Health, vol. 9, no. 4, pp. 685-696, 2017.

[17] A. Delepierre, A. Gayot, and A. Carpentier, "Update on counterfeit antibiotics worldwide; public health risks," Medecine et maladies infectieuses, vol. 42, no. 6, pp. 247-255, 2012.

[18] D. A. Goldmann, "Strategies to prevent and control the emergence and spread of antimicrobial-resistant microorganisms in hospitals: a challenge to hospital leadership," JAMA, vol. 275, no. 3, pp. 234-240, 1996.

[19] M. Cheesbrough, District Laboratory Practice in Tropical Countries, Cambridge University Press, 2006.

[20] A. W. Bayer, W. M. M. Kirby, J. C. Sherris, and M. Turck, "Antibiotic susceptibility testing by a standardized single Disk method," American Journal of Clinical Pathology, vol. 45, no. 4_ts, pp. 493-496, 1966.

[21] S. A. M. Abdulrahman and K. Basavaiah, "Use of bromatebromide mixture as a reagent for the determination of dothiepin hydrochloride in pharmaceuticals," Thai Journal of Pharmaceutical Sciences, vol. 35, no. 4, 2011.

[22] A. S. Alabi, L. Frielinghaus, H. Kaba et al., "Retrospective analysis of antimicrobial resistance and bacterial spectrum of infection in Gabon, Central Africa," BMC Infectious Diseases, vol. 13, no. 1, p. 455, 2013.

[23] F. Schaumburg, B. Biallas, E. Ngoune Feugap et al., "Carriage of encapsulated bacteria in Gabonese children with sickle cell anaemia," Clinical Microbiology and Infection, vol. 19, no. 3, pp. 235-241, 2013.

[24] T. V. Mhada, F. Fredrick, M. I. Matee, and A. Massawe, "Neonatal sepsis at Muhimbili National Hospital, Dar es Salaam, Tanzania; aetiology, antimicrobial sensitivity pattern and clinical outcome," BMC Public Health, vol. 12, no. 1, p. 904, 2012.

[25] J. Mohammed, "Antimicrobial resistance among clinically relevant bacterial isolates in Accra: a retrospective study," BMC Research Notes, vol. 11, no. 1, p. 254, 2018.

[26] World Health Organization, Essential Drugs Monitor: antimicrobial drug resistance: a global treat, World Health Organization, Geneva, Switzerland, 2000.

[27] A. Asensio, T. Alvarez-Espejo, J. Fernandez-Crehuet et al., "Trends in yearly prevalence of third-generation cephalosporin and fluoroquinolone resistant Enterobacteriaceae infections and antimicrobial use in Spanish hospitals, Spain, 1999 to 2010," Eurosurveillance, vol. 16, no. 40, 2011.

[28] R. Polse, S. Yousif, and M. Assafi, "Prevalence and antimicrobial susceptibility patterns of uropathogenic E. coli among people in Zakho, Iraq," International Journal of Research in Medical Sciences, vol. 4, no. 4, pp. 1219-1223, 2016. 
[29] S. Sabir, "Isolation and antibiotic susceptibility of E. coli from urinary tract infections in a tertiary care hospital," Pakistan Journal of Medical Sciences, vol. 30, no. 2, pp. 389-392, 2014.

[30] S. Eshetie, F. Tarekegn, G. Kumera, and F. Mekonnen, "Multidrug resistant Escherichia coli strains isolated from urine sample, University of Gondar Hospital, Northwest Ethiopia," Journal of Coastal Life Medicine, vol. 4, no. 2, pp. 140-142, 2016.

[31] F. Gashe, E. Mulisa, M. Mekonnen, and G. Zeleke, "Antimicrobial Resistance Profile of Different Clinical Isolates against Third- Generation Cephalosporins," Journal of Pharmaceutics, vol. 2018, Article ID 5070742, 7 pages, 2018.

[32] H. B. V. Kumari, S. Nagarathna, and A. Chandramuki, "Antimicrobial resistance pattern among aerobic gram-negative bacilli of lower respiratory tract specimens of intensive care unit patients in a neurocentre," Indian Journal of Chest Diseases and Allied Sciences, vol. 49, no. 1, pp. 19-22, 2007.

[33] P. Gunjal, S. Gunjal, and S. Kher, "A cross-sectional study to determine the profile and antibiotic resistance pattern of gram negative bacilli isolated from intensive care unit patients in a tertiary care hospital in Ahmednagar, Maharashtra," International Journal of Biomedical and Advance Research, vol. 3, no. 5, pp. 281-284, 2012.

[34] World Health Organization, "Global antimicrobial resistance surveillance system: manual for early implementation," World Health Organization, 2015.

[35] A. S. Moini, B. Soltani, A. T. Ardakani et al., "Multidrug-resistant Escherichia coli and Klebsiella pneumoniae isolated from patients in Kashan, Iran," Jundishapur Journal of Microbiology, vol. 8, no. 10, 2015.

[36] F. Fallah, S. Parhiz, and L. Azimi, "Distribution and antibiotic resistance pattern of bacteria isolated from patients with community-acquired urinary tract infections in Iran: a crosssectional study," International Journal of Health Studies, vol. 4, no. 2, 2019.

[37] M. B. Kays, D. W. Smith, M. F. Wack, and G. A. Denys, "Levofloxacin treatment failure in a patient with fluoroquinoloneresistant Streptococcus pneumoniae pneumonia," Pharmacotherapy, vol. 22, no. 3, pp. 395-399, 2002.

[38] R. Davidson, "Resistance to levofloxacin and failure of treatment of pneumococcal pneumonia," The New England Journal of Medicine, vol. 346, no. 10, pp. 747-750, 2002.

[39] H. Seok, C.-I. Kang, K. Huh et al., "Risk factors for community-onset pneumonia caused by levofloxacinnonsusceptible streptococcus pneumoniae," Microbial Drug Resistance, vol. 24, no. 9, pp. 1412-1416, 2018.

[40] D. Beyene, A. Bitew, S. Fantew, A. Mihret, and M. Evans, "Multidrug-resistant profile and prevalence of extended spectrum $\beta$-lactamase and carbapenemase production in fermentative Gram-negative bacilli recovered from patients and specimens referred to National Reference Laboratory, Addis Ababa, Ethiopia," PLoS One, vol. 14, no. 9, article e0222911, 2019.

[41] F. Rosso, J. A. Cedano, L. G. Parra-Lara et al., "Emerging carbapenem-resistant Aeromonas spp. infections in Cali, Colombia," Brazilian Journal of Infectious Diseases, vol. 23, no. 5, pp. 336-342, 2019.

[42] A. Jahansepas, "Occurrence of Enterococcus faecalis and Enterococcus faecium in various clinical infections: detection of their drug resistance and virulence determinants," Microbial Drug Resistance, vol. 24, no. 1, pp. 76-82, 2018.
[43] R. Nikoo, A. A. Hadi, and J. Mardaneh, "Systematic review of antimicrobial resistance of clinical Acinetobacter baumannii isolates in Iran: an update," Microbial Drug Resistance, vol. 23, no. 6, pp. 744-756, 2017.

[44] B. Soltani, H. Heidari, H. S. Ebrahim-Saraie, N. Hadi, J. Mardaneh, and M. Motamedifar, "Molecular characteristics of multiple and extensive drug-resistant Acinetobacter baumannii isolates obtained from hospitalized patients in Southwestern Iran.," Le infezioni in medicina, vol. 26, no. 1, pp. 67-76, 2018.

[45] Z. Farshadzadeh, F. B. Hashemi, S. Rahimi et al., "Wide distribution of carbapenem resistant Acinetobacter baumannii in burns patients in Iran," Frontiers in microbiology, vol. 6, article 1146, 2015.

[46] J. Mardaneh and M.-M. Soltan-Dallal, "Isolation and identification of E. cowanii from powdered infant formula in NICU and determination of antimicrobial susceptibility of isolates," Iranian Journal of Pediatrics, vol. 24, no. 3, p. 261, 2014.

[47] M. Mama, A. Abdissa, and T. Sewunet, "Antimicrobial susceptibility pattern of bacterial isolates from wound infection and their sensitivity to alternative topical agents at Jimma University Specialized Hospital, South-West Ethiopia," Annals of Clinical Microbiology and Antimicrobials, vol. 13, no. 1, p. 14, 2014.

[48] A. Yishak and L. W. Biruk, "Microbial susceptibility of bacteria isolated from open fracture wounds presenting to the BlackLion Hospital, Addis Ababa University," African Journal of Microbiology Research, vol. 3, pp. 939-951, 2009.

[49] W. Mulu, B. Abera, M. Yimer, T. Hailu, H. Ayele, and D. Abate, "Bacterial agents and antibiotic resistance profiles of infections from different sites that occurred among patients at Debre Markos Referral Hospital, Ethiopia: a cross-sectional study," BMC Research Notes, vol. 10, no. 1, p. 254, 2017.

[50] E. Drougka, A. Foka, A. Liakopoulos et al., "A 12-year survey of methicillin-resistant Staphylococcus aureus infections in Greece: ST80-IV epidemic?," Clinical Microbiology and Infection, vol. 20, no. 11, pp. O796-O803, 2014.

[51] G. Sakoulas and R. C. Moellering Jr., "Increasing antibiotic resistance among Methicillin-Resistant Staphylococcus aureus Strains," Clinical Infectious Diseases, vol. 46, Supplement 5, pp. S360-S367, 2008.

[52] D. Zare, H. Fazeli, and S. Moghim, "Antimicrobial resistance pattern and spectrum of multiple-drug-resistant enterobacteriaceae in Iranian hospitalized patients with cancer," Advanced Biomedical Research, vol. 7, no. 1, p. 69, 2018.

[53] J.-M. Rolain, C. Abat, M.-T. Jimeno, P.-E. Fournier, and D. Raoult, "Do we need new antibiotics?," Clinical Microbiology and Infection, vol. 22, no. 5, pp. 408-415, 2016. 